\title{
A paz e as religiões
}

\author{
PAULO EVARISTO, CARDEAL ARNS
}

\section{Da Antigüidade aos Papas de hoje}

$\mathrm{H}$

Esíodo, inspirador de gerações de poetas, escritores e heróis, foi quem procurou colocar ordem nas crenças dos gregos. Nasceu assim sua teogonia. O lugar que coube à deusa da Paz, Eirene, foi como uma das três "horas", filha do próprio Zeus - o deus dos deuses - e de Temis, que por sua vez foi apresentada como filha do céu e da terra, aquela que nutria e profetizava. Temis, a mãe de Eirene, passará mais tarde a ser considerada pelos romanos como a Justiça.

Enquanto os gregos ofereciam sacrifícios a outras divindades, a deusa Paz nunca os recebia. Entre as mais célebres estátuas gregas passou a figurar o grupo Eirene, Paz, carregando a Ploutos, Riqueza. Esta riqueza não é, todavia, dominadora, e sim uma criança de colo acariciando com inefável doçura o queixo de sua mãe Paz. Essa estátua, esculpida pelo pai e mestre de Praxíteles, conquista de tal forma o coração dos atenienses que eles a gravam também em suas moedas.

$\mathrm{O}$ povo que no mundo melhor representou o ideal humanista teve sempre nos seus bolsos e diante dos olhos a imagem carinhosa da mãe chamada Paz, única a proporcionar-lhe abundância e relações amistosas com outros povos.

E, no entanto, a guerra destruiu Atenas!

Entre os romanos, foi difícil chegar ao ideal expresso por Tácito: "A todos seduziu a paz com a doçura da tranqüilidade" (Cunctos dulcedine otii pellexitAnnales I, 2, 1). Custou a implantar-se o culto da paz entre os povos que, aos poucos, foram compondo a nação romana. No entanto, no ano 9 a. C., erigiu-se o altar da Paz Augusta no próprio Campo de Marte, deus da guerra, por resolução do Senado. Assim, o governo imperial se tornou, por isso mesmo e a um tempo, forte e popular, acabando portanto os romanos por prestar à Paz os mesmos atributos que prestavam à fortuna e à abundância, representada pelo ramo de oliveira e outros símbolos, e passando às vezes a colocar nas mãos da Paz a lança, em seu corpo asas e, sobre a cabeça, louros. Mesmo no tempo em que a paz era mais uma garantia de posse do que um convite para a justiça, a colaboração e a convivência, ergueu-se o templo da Paz numa esplanada que ostentava o pomposo nome de Fórum da Paz, muito embora viessem parar neste mesmo templo, por ironia da História, os despojos trazidos da conquista de Jerusalém.

A paz, de fato, não chegara a vencer, nem a convencer, os romanos belicosos.

Poderíamos, aqui, contar a história de cada um ou de muitos povos, e chegaríamos à conclusão de que, infelizmente, o heroísmo era medido pelo sangue derramado e não pela virtude, $\mathrm{o}$ trabalho e as condições implantadas em cada um 
deles. Ainda hoje se escrevem livros de História assinalando etapas a partir de guerras e revoluções, e não a partir de movimentos que levaram os povos a empenhar-se em favor do bem comum e da redenção dos marginalizados e esquecidos pela sorte.

Chegamos a uma época nova e a concepções revolucionárias também no terreno da paz. É preciso que se repitam e se reproduzam gestos capazes de arrastar gerações inteiras para nova orientação. É só prestarmos atenção à profusão de notícias disponíveis pelos mais modernos e avançados meios de comunicação, a respeito de iniciativas, algumas muito originais e criativas, de grupos e organizações, religiosas ou não, que se dedicam com esmero e eficiência à causa da paz em seus ambientes e nas mais diversificadas áreas de atuação.

A Igreja que represento, realizadora do memorável Concílio Ecumênico Vaticano II no recém-findo século XX, produziu naquela histórica assembléia uma série de documentos de fundamental importância para a sua própria vivência, dos quais um deles, intitulado A Igreja e o Mundo ${ }^{1}$ (Gaudium et Spes) - o único da série em que os leigos do mundo inteiro colaboraram de maneira eficiente e prolongada - fez os bispos dos cinco continentes, assumindo a função de portavozes de cristãos e não-cristãos, proclamarem o princípio: "Nada aproveita aos chefes de Estado que insistam na construção da paz enquanto sentimentos de hostilidade, desprezo ou desconfiança, ódios raciais e ideologias obstinadas dividem os homens em campos opostos" (nํㅛ 82).

Seguindo a orientação do Concílio, já o saudoso Papa Paulo VI confiava a um de nossos bispos brasileiros que não nos contentássemos com conversas e negociações de cúpula, mas confiássemos os movimentos de paz aos jovens, aos profissionais da mídia, aos operários e às famílias.

Passadas praticamente quatro décadas desde esse conselho do saudoso Papa que me fez bispo da Igreja, vem João Paulo II, grande arauto da Paz, ainda há poucas semanas discursar ao Presidente norte-americano George Bush, por ocasião da visita deste ao Vaticano, em 4 de junho p.p. O tema do Papa não poderia ser outro senão a Guerra do Iraque e da Terra Santa que, numa sucessão interminável de meses, ocupa os principais espaços da mídia com explosões, atentados, morticínios e banhos de sangue que envergonham nossa triste humanidade contemporânea. Ouçamos algumas palavras desse ancião admirável, que vai se consumindo no esforço permanente e na esperança de fazer sua voz ouvida:

Senhor Presidente, sua visita a Roma ocorre num momento de grande preocupação pela constante situação de grave desordem no Oriente Médio, seja no Iraque, seja na Terra Santa. O senhor conhece perfeitamente a posição inequívoca da Santa Sé a respeito deste assunto. Ela foi expressa em numerosos documentos, através de contatos diretos e indiretos, e das muitas tratativas diplomáticas havidas desde que o senhor me visitou, pela primeira vez, em Castelgandolfo, em 23 de julho de 2001, e depois neste Palácio Apostólico, em 28 de maio de 2002. 


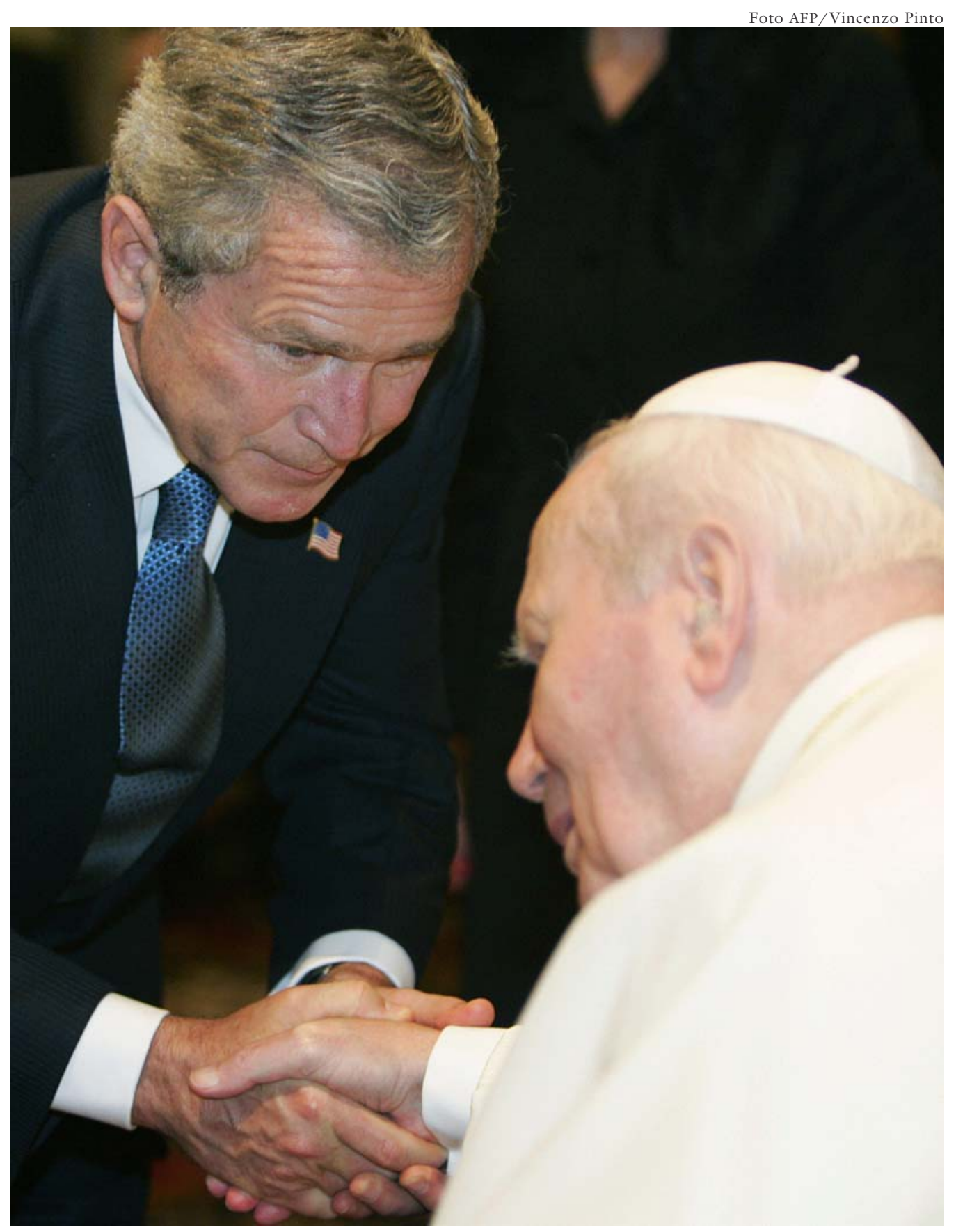

O presidente George W. Bush foi recebido pelo Papa João Paulo II no último dia 4 de junho.

É evidente o desejo de cada um, de que esta situação se normalize o mais rapidamente possível, com a participação ativa da comunidade internacional, particularmente da Organização das Nações Unidas, a fim de garantir um rápido retorno da soberania do Iraque, em condições de segurança para todo o seu povo. A recente nomeação do Chefe de Estado no Iraque e a formação de um governo iraqueano interino são passos encorajadores rumo à conquista deste objetivo. Que uma esperança de paz semelhante desponte 
igualmente na Terra Santa, conduzindo a novas negociações, ditadas por um empenho sincero e determinado ao diálogo entre o Governo de Israel e a Autoridade Palestina.

A ameaça do terrorismo internacional continua a ser uma fonte de constante preocupação. Ela influi gravemente nas relações normais entre os Estados e os povos, desde a trágica data de 11 de setembro de 2001, a qual não hesitei em definir como "dia tenebroso na história da humanidade". Nestas últimas semanas aconteceram e foram exibidos outros eventos deploráveis, que perturbaram a consciência civil e religiosa de todos, tornando ainda mais difícil o empenho sereno e resoluto na partilha dos valores humanos: na falta deste empenho a guerra e o terrorismo jamais poderão ser superados.

Que Deus conceda força e sucesso a todos quantos não cessam de esperar e de agir em favor da compreensão entre os povos, no respeito pela segurança e pelos direitos de todas as nações, de cada homem e de cada mulher!

$[\ldots]$

Que Deus conceda paz e liberdade a toda a humanidade!

Mais recentemente ainda, no início de setembro passado, João Paulo II confortou a todos os povos que amam a Paz, ao enviar o seguinte telegrama ao Núncio Apostólico de Moscou:

Ao tomar conhecimento do violento epílogo do feroz seqüestro na Ossétia do Norte, com a infame agressão contra crianças e famílias indefesas, o Papa expressa sua solidariedade ao povo russo, nesta hora de apreensão e angústia, especialmente aos familiares dos mortos e feridos. O Papa confia à misericórdia do Senhor, as vítimas inocentes desta tragédia, implorando pelo seu eterno repouso. Mais uma vez, o Papa deplora toda forma de terrorismo e faz votos para que não prevaleça a espiral de ódio e de violência. Por fim, implora à Virgem santa, tão venerada pelos cristãos russos, que suscite no coração de todos, pensamentos de sabedoria e propósitos de paz e reconciliação.

\section{A paz dos que professam religião}

O tema para o encontro de hoje - A paz e as religiões - me foi sugerido no ano passado pelos companheiros do Conselho Deliberativo do Instituto de Estudos Avançados da USP. Não foi por causa do $30^{\circ}$ aniversário da minha nomeação como Cardeal de São Paulo, que então ocorria. Razões de saúde e, mais recentemente, a greve da nossa Universidade, foram o motivo de somente agora podermos concretizar este evento.

A solenidade do cardinalato, embora realizada há 31 anos, me faz evocar aqui a palavra que nos foi transmitida naquele momento pelo colega de turma italiano, Dom Albino Luciani, então Patriarca de Veneza e, cinco anos depois, o Papa-sorriso, João Paulo I. Sua saudação abordava este nosso tema de hoje. Após realçar que a paz podia ser alcançada e tornar-se justa e duradoura se afastássemos os males da terra que mais irritavam os homens, o mesmo orador prome- 
teu ao Papa (Paulo VI) que os 31 Cardeais da turma participariam em todo ecumenismo autêntico que se realizasse em qualquer lugar da terra.

De fato, a promoção da paz no mundo é intrinsecamente ecumênica e inter-religiosa.

O humanismo, tanto o antigo quanto o renascentista, separava o termo PAZ de seu significado bíblico, embora os cristãos continuassem a inspirar-se no modelo de Jesus Cristo.

Os movimentos dos séculos XIX e XX foram ainda mais longe. Cada filosofia, cada ideologia, cada visão política, cultural e social caracterizou a paz a seu modo. O termo bíblico chega a diluir-se, embora por vezes fecunde e enriqueça o significado moderno.

Se perguntássemos a um homem da rua e ao mais alto responsável pelos destinos de uma nação, quais os elementos da paz, talvez ambos insistissem no perigo contínuo da guerra e na possibilidade de auto-aniquilação. Respeitáveis em si, esses elementos não chegam a ser positivos, nem duradouros, porque não tomam em conta a fonte da paz que é o amor, a segurança interna e externa e ainda a construção de algo em comum. Para não sermos utópicos, deveríamos sempre levar a compreensão humana para a construção positiva e não apenas para o medo e a autodefesa.

Em uma primeira consideração, quase todos chegam a entender o conceito exposto por Santo Agostinho e repetido ao longo dos séculos: que a paz seja a conservação da ordem total, eliminando luta de classes e diferenças injustas. O grande teólogo da Antigüidade não defende porém a ordem injusta, e sim a evolução dessa mesma ordem e sua adaptação ao tempo.

Houve eras em que se pretendia alcançar a paz sem a participação do escravo. Em outros tempos, ignoravam-se as aspirações da mulher. Nos dias de hoje, porém, a paz já não é tarefa nem privilégio de uma classe, muito menos responsabilidade única de autoridades. Para tal tarefa costumam ser convocados todos os que possuem carisma especial, mas nem mesmo esses líderes deixarão de provocar anarquia em vez de paz, se não acordarem as forças vivas de todas as pessoas capazes de amar e se não confiarem a todos essa tarefa comum, esse objetivo último. Atenção, no entanto: ao confiarmos até às crianças e aos idosos a missão da paz, não podemos entendê-la apenas em sentido horizontal. É preciso que em toda parte existam cisternas de sabedoria, fontes de paz em que se alimente a reflexão e a tarefa dos demais.

Para criarmos clima de paz e não operarmos apenas através de slogans e de argumentos ocasionais, seria necessário descermos às profundezas da natureza humana, às peculiaridades de cada ser e às aspirações autênticas dos grupos. Melhor ainda, deveríamos descobrir como se alimentam as raízes do nosso ser, para que elas produzam o fruto da paz.

Nossa vontade de indivíduos que professam uma religião se volta para a Paz, porque nascemos de um Ser supremo, Deus, que se comunica com suas 
criaturas, está presente em todos os seus relacionamentos e impulsiona os mesmos seres humanos a se comunicarem entre si.

A religião só é autêntica enquanto mantém despertada a consciência humana. Na hora em que é instrumentalizada para adormecer a mesma consciência, ela perde o direito de chamar-se religião.

A religião autêntica preocupa-se ainda em formar seus adeptos de modo a exercerem um juízo crítico sobre a guerra; a refletirem continuamente sobre as condições para a paz mundial, transformando o resultado disso em tema e conteúdo de orações e preces; a rejeitarem a guerra global e todas as formas de contendas; a clamarem contra o armamento das nações; a usarem a mídia para estabelecer clima de paz; e a exigirem negociações em vez de soluções violentas.

Espera-se ainda que as religiões se transformem em estímulo contínuo para o amor fraterno, o perdão e o desenvolvimento, estabelecendo condições para que uma era possa ligar-se à outra com a participação e a co-responsabilidade de todos os adeptos.

\section{A USP, a paz entre as religiões e a Igreja de São Paulo}

Durante a cerimônia a que me referi há pouco, o Consistório cardinalício de março de 1973, no momento de jurar fidelidade ao Papa eu tinha à minha direita e esquerda dois Cardeais africanos, que se entusiasmaram com o assunto do ecumenismo: o Cardeal Tomko, com quase 1,90 m de altura, e o Cardeal Biyayenda, com pouco mais de um metro e meio. Tive então de fazer um esforço "ecumênico" com os dois, porque um deles só entendia o inglês, língua estranha à África, e o outro se expressava em francês, aliás, muito elegante, enquanto o cerimonial se desenrolava em italiano.

De fato, agora estamos na USP, uma semana apenas depois desse episódio "ecumênico", acudindo como Cardeal novo a acontecimentos que viriam contribuir decisivamente para uma nova ordem no Brasil: fui procurado à noite em minha casa, lá pelas 22 ou 23 horas, por um grupo grande de universitários que eram os presidentes de nossos Diretórios Acadêmicos. Motivo: naquele momento estavam cercados na Cidade Universitária pelas tropas de Erasmo Dias, então Secretário da Segurança Pública. Pediam-me eles nada menos do que acompanhálos para evitar uma explosão de violência. Ao sair daquele cerco ditatorial, certamente muitos deles seriam atingidos por balas e nada poderíamos fazer naquela hora da noite, para sossegar a impaciência dos estudantes.

Afinal, após longo diálogo, chegamos à conclusão de eu deveria remeter uma mensagem aos estudantes, prometendo celebrar na Catedral Metropolitana a missa pelo jovem Alexandre Vannucchi Leme, do curso de Arquitetura, que acabara de ser morto pela repressão, motivando essa reunião, embora também outros colegas sofressem da crueldade tão conhecida da ditadura militar.

A missa de fato se realizou às quinze horas da segunda-feira seguinte, com a presença maciça de estudantes, pais e mestres. No meu sermão não hesitei em 
dizer a todo o público que, no centro dos dez mandamentos de Deus, encontrava-se a ordem divina: "Não matarás".

Apesar de toda a angústia que cercava a nossa USP tão querida - e mesmo os pais e mestres de outras escolas - nós conseguimos que esse ato fosse noticiado não só em muitos lugares no Brasil, mas igualmente pelas agências internacionais de notícias.

Estudantes começavam a abalar o edifício de uma ditadura que iria prolongar-se até 1985, portanto, por doze anos ainda.

Trago comigo um relatório das outras iniciativas ecumênicas de meu tempo de Arcebispo, algumas delas patrocinadas pela Igreja Presbiteriana e, mais tarde, pelo Conselho Mundial de Igrejas de Genebra. Entre tantas reuniões, eu gostaria de realçar dois exemplos: uma outra Universidade - Notre Dame de Indiana, EE.UU. - que em 1977 me confiaria o Doutorado Honoris Causa junto com o Presidente Jimmy Carter - me convocou em 1975 para proferir a oração de abertura e para participar da reunião das religiões monoteístas em Bellagio, Itália. Nosso objetivo era claro: convidar as pessoas da mais alta consideração no undo, para que as nações em guerra - sobretudo, então, o Egito e Israel - en-v iassem representantes ao evento. Nossa intenção era sempre procurar o diálogo evitar derramamento de sangue. De fato, numa manhã, eu me encontrei com o inistro do Egito sozinho, meditando, naquela belíssima região da Itália, e pedi icença para propor-lhe uma questão: a paz é possível, ou ainda teremos que sperar muito tempo para que os ânimos se acalmem? Para meu espanto, ele espondeu: "Tomara que nunca tivesse havido guerra, nem aquele atentado terrível que ceifou a vida de nosso Presidente e de tantos companheiros corajosos e em intencionados!”

segunda reunião desse grupo realizou-se em Cascais, Lisboa, que naquele momento estava sem turistas e estrangeiros que pudessem influir num encontro tido como informal, mas muito realista. Tivemos então apenas a visita do residente Soares e do Cardeal-Patriarca local, Dom Antonio Ribeiro. Infelizmente, não chegamos a grandes conclusões, pelas mais diversas interferências, mbora todas as religiões ali representadas, como em Bellagio, participassem da rece matinal pela paz e, à noite, celebrassem em seu próprio rito outras orações a mesma intenção.

ão alcançamos, portanto, nossos objetivos embora tivéssemos o apoio os maiores especialistas nos diversos assuntos aventados na reunião. Na minha embrança se fixou a expressão de um general muçulmano, que me disse, com toda simplicidade: "É preciso atacar os motivos da tensão e não os erros cometidos nas negociações. O povo forma a opinião sempre a partir de quem tem a palavra mais envolvente e a arma mais poderosa. E há um outro motivo: a paz depende da liderança de todos os setores humanos, desde a economia até os incidentes de fronteira". Acrescentou ainda, com muita calma: "O que importa é que a juventude participe dessas tentativas de paz nos mais diversos setores que 
são abordados nas universidades, e que, por meio dessa juventude, todas as idades e organizações sociais estejam presentes, quando convocadas para as manifestações de paz".

Naquela mesma ocasião, ouvi pela primeira vez a menção a um código mínimo de ética para a convivência humana. Para mim, até então, o instrumento mais convincente era a Declaração Universal dos Direitos Humanos, promulgada em 10 de dezembro de 1948. Contou-me uma pessoa muito achegada ao alto escalão dos Estados Unidos, que a própria senhora Roosevelt, incentivada pelo marido, havia conseguido a última subscrição indispensável à aprovação do documento quase à zero hora do próprio dia da promulgação.

\section{Algumas pistas para a ação}

Mas eu estou falando na USP, e é neste lugar que fui, pela primeira vez, convocado, na qualidade de Cardeal da Igreja, como descrevi há pouco, para promover um ato decisivo - depois da morte de Alexandre Vannucchi Leme - a fim de salvar centenas de vidas. É por isso que eu venho propor alguns pontos práticos que certamente deverão ser completados pelos senhores, em todos os Departamentos da nossa querida USP:

- A primeira condição para que um estudante possa entusiasmar-se pela paz entre as religiões é oferecer-lhe possibilidades para o conhecimento delas e suas propostas para a prática da ética e da solidariedade. Guardo com carinho o livro do professor e teólogo suíço Hans Küng, hoje Presidente da Fundação de Ética Global em Tübingen, Alemanha, intitulado Ja zum Weltethos. Logo no início da famosa exposição feita num imenso estádio de Chicago, nos Estados Unidos, em 1993, pronunciou aquela frase que se tornaria depois orientação para os trabalhos:

Não haverá ordem justa no mundo, sem haver primeiro o ethos mundial. Quando falamos de ethos mundial, não nos referimos a uma nova ideologia nem a uma religião mundial unitária, além de todas as religiões existentes, e muito menos ainda à dominação de uma religião sobre as outras. Quando falamos de ethos mundial, referimo-nos a um consenso fundamental sobre valores existentes, critérios inamoviveis e posturas pessoais básicas, que já existem. Sem um consenso fundamental relativo ao ethos, toda e qualquer comunidade estará ameaçada mais cedo ou mais tarde pelo caos ou por uma ditadura, levando os indivíduos ao desespero.

Este ethos deve penetrar a política, a cultura, e ser apoiado por todas as grandes religiões, que precisam entrar decididamente em uma luta pela paz mundial.

- Uma outra condição que me parece igualmente importante, senão indispensável, é termos pessoas à disposição, que possam atrair e esclarecer os estudantes e, quem sabe, algum mestre menos informado. Em certas horas e ocasiões temos que expor os princípios da ética e do direito das pessoas, sem com isso fundar novas cadeiras, que sempre atingem apenas uma parte 
dos estudantes. Acredito que todos os jovens são amigos da paz e da liberdade, e apóiam os movimentos de solidariedade.

- Atrevo-me a acrescentar mais uma condição que me parece oportuna: aproveitar os momentos de crise para fomentar a reflexão sobre o autêntico destino da humanidade e de cada ser humano. Reconhecer todas as filosofias da vida que se baseiam em motivações positivas, sobretudo quando são enraizadas entre os povos, como acontece na África, na Ásia e em outras partes. Seria mesmo ideal - como me dizia o saudoso Cardeal africano Otunga, que foi meu companheiro de turma no cardinalato - se o mundo respeitasse uma África e uma Ásia, que têm outros conceitos sobre a autoridade e a transmissão de cargos, ajudando-as apenas a viverem em paz, e não entregando-lhes armas para enriquecer a países do Primeiro Mundo.

- Gostaria ainda de acrescentar que precisamos descobrir novas lideranças da paz. A Pastoral da Criança, orientada pela Dra. Zilda Arns Neumann, por exemplo, descobriu entre as pessoas mais apagadas - por não terem tido acesso a estudos - uma possibilidade imensa de lutar por um ideal que a todos interessa e, aos poucos, atrai para iniciativas sempre novas. Nesta altura gostaria de lembrar um fato da Bíblia, em que Cristo respondeu aos apóstolos, que se queixavam de alguém que fazia obras extraordinárias sem pertencer ao grupo deles: “Quem não é contra nós é a nosso favor”.

É certo, e assim concluo esta exposição, que tudo isso deve ser levado com muita urgência e eficiência - acentuo a palavra eficiência - às Nações Unidas, para que a juventude que hoje está nas Universidades, e amanhã irá ocupar os cargos de responsabilidade, tenha confiança nos desejos da humanidade que, ainda há pouco, antes da guerra do Iraque, mostrou mais sabedoria do que certos governantes.

A Universidade de São Paulo certamente poderá encarar a sua responsabilidade pela paz com tranqüilidade, se souber conferir a todas as matérias afins um sentido de luta pela paz, justiça, verdade, enfim, pela solidariedade.

Peço licença para acrescentar que, no relatório contendo as atividades havidas em minha Igreja entre os anos de 1970 a 1998, é possível constatar, a meu ver, que o desejo do povo está todo ele marcado pela luta em favor da paz, da justiça e da verdade. Nele também se percebe quanto as religiões do mundo inteiro acolhem a chamada das pessoas responsáveis, como aquelas que são formadas, com o auxílio de todos, nesta nossa queridíssima Universidade.

Nota

l Os documentos oficiais da Igreja Católica costumam tradicionalmente ser identificados em latim, através das duas primeiras palavras de seus textos. É o caso da Constituição Apostólica Gaudium et Spes, literalmente Alegria e Esperança. No 
entanto, não se costuma traduzir tal título ao pé da letra para o português, porque desta forma não estaria indicado o conteúdo deste documento que é o tema $A$ Igreja e o Mundo.

RESUMO - A RESISTÊNCIA à ação violenta só virá quando for despertada a consciência humana. É por isso que o autor apela para as religiões autênticas, esperando que criem condições para a paz mundial, não apenas por orações, mas sobretudo pela formação de um clima de paz mundial. Até agora, pouco se apelou para o mundo das religiões, e menos ainda para a ação da juventude, nesta nova fase de enfrentamento do problema que se torna sempre mais angustiante. $\mathrm{O}$ autor propõe, enfim, que a USP crie condições para preparar os jovens com vistas à sua responsabilidade futura em favor da paz. É preciso iniciar quanto antes e perseverar até onde possível. Uma ética mundial seria certamente bem-vinda nesta hora.

ABSTRACT - THERE WILL only be resistance to violent action when human awareness is awakened. That is why the author appeals to authentic religions, hoping they may create the conditions for world peace - not only through prayers, but above all by establishing a climate of world peace. So far, in this new phase of facing an increasingly agonizing problem, little has been required from the world of religions and still less from young people's initiatives. In brief, the author's proposal is for the University of São Paulo to create the conditions to prepare young people for their future responsibility in favor of peace. This should begin as soon as, and persevere as much as possible. A world ethics would certainly be welcome at this time.

Paulo Evaristo, Cardeal Arns é Arcebispo Emérito de São Paulo, membro representante da sociedade civil no Conselho Deliberativo e Membro Titular da Cátedra Unesco para a Educação da Paz, Direitos Humanos, Democracia e Tolerância do Instituto de Estudos Avançados da USP.

Conferência do Mês do Instituto de Estudos Avançados da USP proferida pelo autor no dia 19 de outubro de 2004.

Texto recebido e aceito para publicação em 19 de outubro de 2004. 